\title{
Nationwide Evaluation of Congenital Hypothyroidism Screening during Neonatal Extracorporeal Membrane Oxygenation
}

\author{
Lisette Leeuwen $^{a, b} \quad$ Arno F.J. van Heijst $^{d}$ Sanne Vijfhuize ${ }^{a, b}$ \\ Leonardus W.J.E. Beurskens ${ }^{a, b}$ Gert Weijman $^{e}$ Dick Tibboel $^{a, b}$
}

Erica L.T. van den Akker ${ }^{c}$ Hanneke IJsselstijn ${ }^{a, b}$

antensive Care and ${ }^{b}$ Department of Pediatric Surgery, and ${ }^{c}$ Division of Pediatric Endocrinology, Department of Pediatrics, Erasmus MC - Sophia Children's Hospital, Rotterdam, dDepartment of Neonatology, Radboud UMC - Amalia Children's Hospital, Nijmegen, and eNational Institute for Public Health and Environment (RIVM), Bilthoven, The Netherlands

\section{Key Words}

Congenital hypothyroidism - Critical illness - Extracorporeal membrane oxygenation - Endocrinology - Euthyroid sick syndrome - Intensive care · Neonatal screening - Neonate . Nonthyroidal illness syndrome $\cdot$ Thyroid hormones

\footnotetext{
Abstract

Background: Thyroid hormone concentrations may deviate from normal values during critical illness. This condition is known as nonthyroidal illness syndrome (NTIS), and it can influence the results of screening for congenital hypothyroidism $(\mathrm{CH})$ during neonatal extracorporeal membrane oxygenation (ECMO). Objectives: To determine the incidence of aberrant $\mathrm{CH}$ screening results in ECMO-treated neonates, to identify possible determinants, and to follow up patients with abnormal thyroid hormone concentrations. Methods: In this retrospective cohort study, we included 168 ECMOtreated neonates admitted from 2004 to 2014 and screened by protocol and divided them into the following 3 groups: group 1 (screened during $E C M O, n=107$ ), group 2 (screened shortly before ECMO, $\mathrm{n}=26$ ), and group 3 (screened shortly
}

after ECMO, $\mathrm{n}=35)$. Results: $\mathrm{CH}$ screening results were aberrant in $67.3 \%(72 / 107)$ of the neonates screened during ECMO, in $73.1 \%(19 / 26)$ of the neonates screened before ECMO, and in $31.4 \%(11 / 35)$ of the neonates screened after ECMO $(p<0.001)$. Of the neonates with an aberrant screening result, all but 2 (i.e. 98\%) had a low thyroxine concentration with a normal thyrotropin concentration at screening, as is seen in NTIS. None was diagnosed with $\mathrm{CH}$. Mortality did not significantly differ between neonates with an aberrant screening result (32.4\%) and neonates with a normal screening result (22.7\%; $p=0.18$ ). Screening before ECMO (OR 5.92; $95 \% \mathrm{Cl} 1.93-18.20$ ), screening during ECMO (OR 4.49; $95 \% \mathrm{CI}$ 1.98-10.19), and a higher Pediatric Logistic Organ Dysfunction-2 score (OR 1.31; 95\% Cl 1.04-1.66) were associated with an aberrant screening result. Conclusions: Aberrant $\mathrm{CH}$ screening results were found in most ECMO-treated neonates screened before or during ECMO, which is likely due to NTIS. Follow-up of thyroid hormone concentrations is best started after recovery from critical illness. Our results suggest that thyroxine therapy is not required during ECMO.

(c) 2016 The Author(s)

Published by S. Karger AG, Basel

\begin{tabular}{ll}
\hline KARGER & $\begin{array}{l}\text { (c) 2016 The Author(s) } \\
\text { Published by S. Karger AG, Basel }\end{array}$ \\
$\begin{array}{l}\text { E-Mail karger@karger.com } \\
\text { www.karger.com/neo }\end{array}$ & $\begin{array}{l}\text { This article is licensed under the Creative Commons Attribution- } \\
\text { NonCommercial-NoDerivatives 4.0 International License (CC BY- } \\
\text { NC-ND) (http://www.karger.com/Services/OpenAccessLicense). } \\
\text { Usage and distribution for commercial purposes as well as any dis- } \\
\text { tribution of modified material requires written permission. }\end{array}$
\end{tabular}

Hanneke IJsselstijn, $\mathrm{MD}, \mathrm{PhD}$

Intensive Care and Department of Pediatric Surgery

Erasmus MC - Sophia Children's Hospital

Wytemaweg 80, NL-3015 CN Rotterdam (The Netherlands)

E-Mail h.ijsselstijn@erasmusmc.nl 


\section{Introduction}

As thyroid hormones are essential for normal brain development, children with congenital hypothyroidism $(\mathrm{CH})$ are at risk for intellectual disability [1]. $\mathrm{CH}$ screening and early treatment have almost eliminated intellectual disabilities caused by untreated $\mathrm{CH}$. In the Netherlands, $\mathrm{CH}$ screening is primarily based on thyroxine (T4) screening with supplementary thyrotropin (TSH) and thyroxinebinding globulin measurements aimed at identifying not only children with primary hypothyroidism but also children with central hypothyroidism [2]. However, interpretation of the screening results can be complicated by factors that can transiently reduce thyroid hormone concentrations, such as prematurity [3], drug use [4], cardiac surgery [5], and critical illness [6]. This condition of disturbed thyroid hormone concentrations (low T4 and low triiodothyronine, increased reverse triiodothyronine, and normal or low TSH) during critical illness is referred to as nonthyroidal illness syndrome (NTIS) or euthyroid sick syndrome. It is important to distinguish between $\mathrm{CH}$ and NTIS because $\mathrm{CH}$ therapy should be initiated as soon as possible, whereas treatment for NTIS is not recommended [6]. In previous studies critically ill neonates have had lower thyroid hormone concentrations than healthy neonates [7-9], and this has been associated with a prolonged hospital stay and a higher mortality [7, 9]. Low thyroid hormone concentrations consistent with NTIS have been found in neonates on extracorporeal membrane oxygenation (ECMO) [10]. However, it is unknown whether ECMO exerts an influence on $\mathrm{CH}$ screening results and whether there are any implications of a positive $\mathrm{CH}$ screening result during ECMO. We therefore wanted to determine the incidence of aberrant $\mathrm{CH}$ screening results in ECMO-treated neonates, identify possible determinants of aberrant screening results, and follow up neonates with abnormal thyroid hormone concentrations.

\section{Materials and Methods}

\section{Patients}

In this retrospective cohort study, we included ECMO-treated neonates admitted between January 1, 2004, and December 31, 2014, who underwent $\mathrm{CH}$ screening in either of the two pediatric ECMO centers in the Netherlands [i.e. Erasmus MC-Sophia Children's Hospital (Rotterdam) and Radboud UMC-Amalia Children's Hospital (Nijmegen)]. These centers use the same entry criteria and treatment protocols, but the prime fluid is different: erythrocyte concentrate is used in the Erasmus MC-Sophia Children's Hospital, and erythrocyte concentrate with fresh frozen plasma (FFP) is used in the Radboud UMC-Amalia Children's Hospital.
ECMO was initiated in case of reversible severe respiratory failure with an estimated mortality risk $>80 \%$ as described by Stolar et al. [11]. The exclusion criteria were: screening not in conformity with the Dutch neonatal screening protocol, incomplete or no screening results available, no registration in the Dutch civil registry (not invited for screening), and ECMO initiated after 8 days of life (not critically ill at the scheduled time of screening). We created the following 3 groups: group 1 (screened during ECMO), group 2 (screened shortly before ECMO), and group 3 (screened shortly after ECMO). Neonates in groups 2 and 3 were considered critically ill at screening, but they did not receive ECMO at that time. $\mathrm{CH}$ screening results were obtained from the National Institute for Public Health and Environment (RIVM). In the Netherlands, $\mathrm{CH}$ screening is primarily based on T4 measurements by immunochemical blood spots sampled $72-168 \mathrm{~h}$ after birth. The method is described in detail in the supplementary material (for all online suppl. material, see www.karger.com/doi/10.1159/000448238). We classified the initial screening results as either normal or aberrant (abnormal or borderline result on the first heel puncture). In neonates with an aberrant result, the pattern of changes in thyroid hormone concentrations was classified into 3 categories: abnormally low T4 $[\leq-3.0$ SD score (SDS)] with normal TSH $(\leq 7 \mathrm{mU} / \mathrm{l})$, mildly lowered T4 $(-3.0<\mathrm{T} 4 \leq-1.6 \mathrm{SDS})$ with normal TSH $(\leq 7 \mathrm{mU} / \mathrm{l})$, and mildly lowered T4 $(-3.0<\mathrm{T} 4 \leq-1.6 \mathrm{SDS})$ with mildly elevated TSH $(7<$ TSH $\leq 21 \mathrm{mU} / \mathrm{l})$. Relevant clinical data were collected. The primary diagnosis was defined as the underlying diagnosis requiring ECMO support. Illness severity was estimated using the Pediatric Risk of Mortality III (PRISM III) score [12], calculated for the first $24 \mathrm{~h}$ of Pediatric Intensive Care Unit (PICU) stay, and the Pediatric Logistic Organ Dysfunction-2 (PELOD-2) score [13], computed for the $24 \mathrm{~h}$ prior to the first heel puncture. Povidoneiodine and radiocontrast materials were not used. Ethical approval was obtained from the local ethics committees (CMO 2005/253).

\section{Follow-Up of Neonates with Abnormal Thyroid Hormone}

\section{Concentrations}

Follow-up serum free T4 (FT4) and TSH concentrations were obtained from the medical charts of neonates with an abnormal $\mathrm{CH}$ screening result. FT4 and TSH were compared to the reference values established by Lem et al. [14]. An abnormal value was defined as $<-2$ SDS or $>+2$ SDS compared to the reference values.

\section{Data Analysis}

Data are expressed as means $\pm S D$, medians (IQR), or numbers (\%), as appropriate. Categorical variables were compared using the $\chi^{2}$ test or Fisher's exact test. Student's t test or a one-way ANOVA was used for normally distributed variables, and the Mann-Whitney U test or the Kruskal-Wallis test was applied for non-normally distributed variables. To correct for multiple testing, the Bonferroni correction was used, and adjusted $\mathrm{p}$ values are given. Univariate logistic regression analyses served to identify associations between clinical variables [primary diagnosis, time of screening (before/during/after ECMO), PRISM III score, PELOD-2 score, and drug usage] and aberrant screening results. Use of the following intravenous drugs $\leq 8 \mathrm{~h}$ prior to screening was recorded: dopamine, dobutamine, furosemide, morphine, fentanyl, and hydrocortisone. From a few hours after administration, these drugs can temporarily affect thyroid hormone concentrations; pretreatment levels are reached within hours after discontinuation of the drug [4, 15-19]. Variables with $\mathrm{p} \leq 0.20$ were included in the multiple logistic re- 
Fig. 1. Flowchart of the study population. ${ }^{1}$ Screening performed too early $(n=1)$ or too late $(\mathrm{n}=82)$.

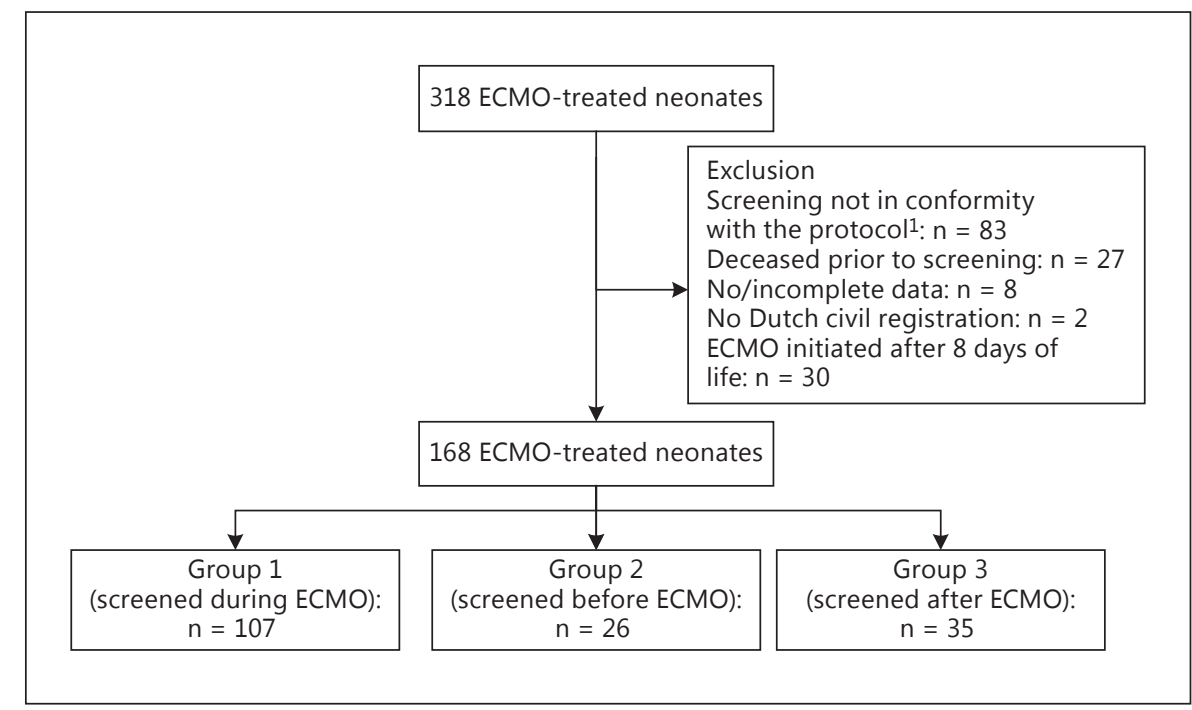

Table 1. Patient characteristics

\begin{tabular}{|c|c|c|c|c|}
\hline Gestational age, weeks & $39.9(38.1-41.0)$ & $40.0(37.0-41.0)$ & $40.4(39.0-41.1)$ & 0.21 \\
\hline Birth weight, $g$ & $3,247 \pm 631$ & $3,256 \pm 704$ & $3,541 \pm 595$ & 0.06 \\
\hline Male sex & $62(57.9)$ & $17(65.4)$ & $20(57.1)$ & 0.77 \\
\hline Primary diagnosis & & & & 0.08 \\
\hline Sepsis & $11(10.3)$ & $3(11.5)$ & $5(14.3)$ & \\
\hline Persistent pulmonary hypertension & $10(9.3)$ & $6(23.1)$ & $8(22.9)$ & \\
\hline Other ${ }^{1}$ & $10(9.3)$ & $2(7.7)$ & $0(0)$ & \\
\hline Age at the start of ECMO therapy, days of life & $1(0-2)$ & $6(5-7)$ & $1(0-1)$ & $<0.001$ \\
\hline Duration of ECMO therapy, days & $7(5-9)$ & $6(4-7)$ & $3(2-4)$ & $<0.001$ \\
\hline PRISM III score (first $24 \mathrm{~h}$ of PICU admission) & $17(15-23)$ & $17(9-21)$ & $17(12-21)$ & 0.12 \\
\hline
\end{tabular}

Data are expressed as means $\pm \mathrm{SD}$, medians (IQR), or numbers $(\%) .{ }^{1}$ Congenital heart disease, congenital cystic adenomatoid malformation, recurrent pneumothoraces, infant respiratory distress syndrome in combination with pneumothorax, meconium peritonitis, respiratory failure of unknown cause.

gression analysis. Multicollinearity was not found. Data were analyzed using SPSS 21.0 for Windows (IBM Corporation, Armonk, N.Y., USA). Statistical significance was accepted at the 5\% level.

\section{Results}

\section{Patients}

ECMO was initiated in 318 neonates (fig. 1). We included 168 neonates divided into 3 groups. Table 1 shows the patient characteristics. In group 3, ECMO was started later, and $\mathrm{CH}$ screening was performed later. Further, the duration of ECMO therapy was shorter in group 3. The median PELOD-2 score was higher in group 1 than in group 3 (adjusted $p=0.045$ ). Eight patients received levothyroxine therapy (online suppl. table 2). Three of them had a normal initial screening result and developed hypothyroxinemia later, which was identified by routine laboratory tests. One patient was diagnosed with thyroid dyshormonogenesis and required lifelong treatment. 
Table 2. $\mathrm{CH}$ screening results

$\begin{array}{lll}\begin{array}{l}\text { Group 1 } \\ (\mathrm{n}=107)\end{array} & \begin{array}{l}\text { Group 2 } \\ (\mathrm{n}=26)\end{array} & \begin{array}{l}\text { Group 3 } \\ (\mathrm{n}=35)\end{array}\end{array}$

\section{Initial screening}

Normal result $\rightarrow$ no further action Abnormal result $\rightarrow$ referral $^{1}$ Abnormally low T4, normal $\mathrm{TSH}^{2}$

Dubious result $\rightarrow$ second screening Mildly lowered T4, normal $\mathrm{TSH}^{3}$ Mildly lowered T4, mildly elevated $\mathrm{TSH}^{4}$

$35(32.7)$
$42(39.3)$
42
$30(28.0)$
28
2

$7(26.9)$
$10(38.5)$
10
$9(34.6)$
9
-

Second screening

Died before the second screening

Normal result $\rightarrow$ no further action

Abnormal result $\rightarrow$ referral $^{1}$

Abnormally low T4, normal $\mathrm{TSH}^{2}$

Mildly lowered T4, normal TSH ${ }^{3}$

Mildly lowered T4, mildly elevated $\mathrm{TSH}^{4}$

$\begin{array}{rrr}1 & 0 & 0 \\ 22 & 9 & 6 \\ 7 & 0 & 0 \\ 1 & - & - \\ 2 & - & - \\ 4 & - & -\end{array}$

${ }^{1}$ To a pediatrician for further analysis. ${ }^{2} \mathrm{~T} 4 \leq-3.0 \mathrm{SDS}$ and $\mathrm{TSH} \leq 7 \mathrm{mU} / 1 .{ }^{3}-3.0<\mathrm{T} 4 \leq-1.6 \mathrm{SDS}$ and $\mathrm{TSH} \leq 7 \mathrm{mU} / 1 .{ }^{4}-3.0<\mathrm{T} 4 \leq$ $-1.6 \mathrm{SDS}$ and $7<\mathrm{TSH} \leq 21 \mathrm{mU} / \mathrm{l}$.

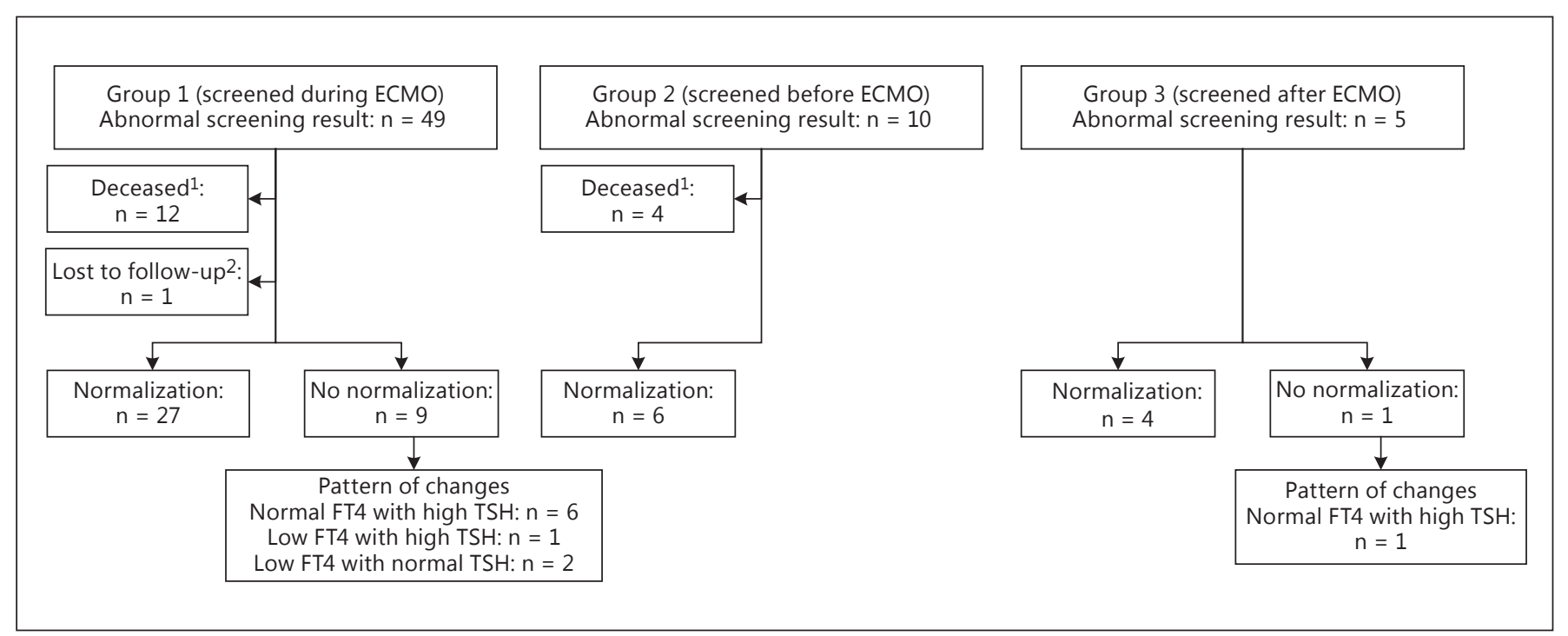

Fig. 2. Follow-up of neonates with abnormal screening results. ${ }^{1}$ Deceased before follow-up of thyroid hormone concentrations was performed. ${ }^{2}$ Transferred to another hospital.

\section{CH Screening Results}

Table 2 shows the screening results. The incidence of aberrant results was higher in group $1(67.3 \%)$ and group $2(73.1 \%)$ than in group $3(31.4 \%$; both adjusted $\mathrm{p}<$ $0.001)$. At the initial screening, the combination of low T4 and normal TSH was found in 100 of 102 neonates (ta- ble 2). Neonates with an aberrant screening result were treated longer with ECMO and had higher PELOD-2 scores than those with a normal screening result (online suppl. table 3). The incidence of aberrant screening results in group 1 in both centers was similar and thus irrespective of the use of FFP in the prime fluid (67.2\% with 
Table 3. Results of logistic regression analyses: clinical variables associated with an aberrant screening result

\begin{tabular}{|c|c|c|c|c|}
\hline & Univariate model & $\mathrm{p}$ value & Multivariate model $^{1}$ & $\mathrm{p}$ value \\
\hline \multicolumn{5}{|l|}{ Time of screening } \\
\hline After ECMO (ref.) & 1.00 & - & 1.00 & - \\
\hline Before ECMO & $5.92(1.93-18.20)$ & 0.002 & $4.59(1.11-18.93)$ & 0.04 \\
\hline During ECMO & $4.49(1.98-10.19)$ & $<0.001$ & $3.19(1.22-8.32)$ & 0.02 \\
\hline PELOD-2 score & $1.31(1.04-1.66)$ & 0.02 & $1.27(0.99-1.63)$ & 0.06 \\
\hline Congenital diaphragmatic hernia & $1.78(0.82-3.89)$ & 0.15 & $1.41(0.60-3.34)$ & 0.44 \\
\hline Others & $1.51(0.73-3.13)$ & 0.27 & $1.34(0.56-3.16)$ & 0.51 \\
\hline \multicolumn{5}{|l|}{ Dopamine } \\
\hline No (ref.) & 1.00 & - & 1.00 & - \\
\hline Yes & $1.63(0.84-3.18)$ & 0.15 & $1.01(0.46-2.21)$ & 0.98 \\
\hline \multicolumn{5}{|l|}{ Morphine } \\
\hline
\end{tabular}

Values are presented as OR (95\% CI). ref. = Reference. ${ }^{1}$ Adjusted OR, adjusted for all other variables shown in the table.

FFP vs. 67.3\% without FFP; $\mathrm{p}=1.00)$. The proportion of aberrant screening results in group 1 was not dependent on the time elapsed between the start of ECMO and blood sampling for $\mathrm{CH}$ screening (data not shown).

\section{Follow-Up of Neonates with Abnormal Thyroid \\ Hormone Concentrations}

The follow-up results are shown in figure 2. Sixteen neonates died before the follow-up was initiated, and 1 was transferred to another hospital. Thyroid hormone concentrations normalized in 37 neonates at the median age of 10 days (IQR 8-17.5). In 29 of those neonates, this happened before 28 days of life; thyroid hormone concentrations normalized in the other 8 neonates between 30 and 108 days of life. Normalization of thyroid hormone concentrations could not be confirmed in 10 children (fig. 2). At the last follow-up, low FT4 values ranged from 12.0 to $12.7 \mathrm{pmol} / \mathrm{l}$ and high TSH values ranged from 5.7 to $14.9 \mathrm{mU} / \mathrm{l}$ in these children.

\section{Aberrant CH Screening Results and Mortality}

The mortality rate before hospital discharge was $28.6 \%$ (48/168). The mortality rate was not significantly higher in children with an aberrant $\mathrm{CH}$ screening result (32.4\%) than in children with a normal screening result $(22.7 \%$; $\mathrm{p}=0.18)$.
Associations between Clinical Variables and an Aberrant CH Screening Result

In the univariate logistic regression analyses, screening before ECMO, screening during ECMO, and a higher PELOD-2 score were significantly associated with an aberrant screening result (table 3 ). In the multivariate model, screening before and during ECMO remained associated with an aberrant screening result.

\section{Discussion}

More than two thirds of the initial $\mathrm{CH}$ screening results were aberrant in ECMO-treated neonates screened before and during ECMO. Low T4 in combination with a normal TSH concentration was found in all but 2 neonates with an aberrant screening result, which normalized rapidly without treatment in most cases. None of these children was diagnosed with $\mathrm{CH}$. This suggests that aberrant screening results are due to NTIS, and that levothyroxine therapy during ECMO is not required. The incidence of aberrant screening results in the group of neonates screened after ECMO was significantly lower than that in the 2 other groups, possibly reflecting that clinical recovery occurs during ECMO.

Reduced thyroid hormone concentrations have been found in critically ill term neonates treated with or without ECMO [7-10]. The effect of neonatal ECMO on thy- 
roid hormone concentrations has been studied only by Stewart et al. [10]. They found a decline in all thyroid hormone concentrations directly after the start of ECMO in a cohort of 14 neonates, which suggests a dilutional effect. Additionally, Agus and Jaksic [20] reported that thyroid hormone concentrations in ECMO prime fluid were significantly below normal. They suggested that these concentrations would be even lower in prime fluid without FFP [20]. However, in the present study the incidence of aberrant screening results was not higher in the center without FFP in the prime fluid. Although we acknowledge that the occurrence of hemodilution after ECMO cannulation plays a role in the lowering of thyroid hormone concentrations, we think that NTIS contributes more to this, and that hemodilution may further lower thyroid hormone concentrations in critically ill neonates. This assumption is supported by our finding that the incidences of aberrant screening results did not significantly differ between screening before (73.1\%) and during (67.3\%) ECMO.

Screening before and during ECMO and a higher PELOD-2 score were associated with an aberrant screening result. Further, neonates with an aberrant screening result had higher PELOD-2 scores than neonates with a normal screening result, suggesting an influence of illness severity. Nevertheless, the use of the PELOD-2 score has some limitations. Though validated for a broad group of PICU patients [13], its performance in ECMO-treated neonates is unknown. Further, the PELOD-2 score is affected by treatment. Therefore, we cannot firmly conclude that illness severity plays a role in causing aberrant screening results.

Dopamine has been found to suppress TSH in previous studies [17, 19], but we did not find an association between dopamine and an aberrant screening result. Therefore, dopamine does not seem to be the main cause of aberrant $\mathrm{CH}$ screening results. However, our study does not allow pinpointing of the exact effect of dopamine on thyroid hormone concentrations.

Now, clinicians will be most concerned with the implications of aberrant $\mathrm{CH}$ screening results. As we found a lower risk of aberrant screening results in neonates screened after ECMO, follow-up of thyroid hormone concentrations should be started after ECMO and ideally after recovery from critical illness. However, because T4 treatment should not be started later than the first 2 weeks of life to prevent intellectual disabilities [21], we recommend that thyroid function tests be repeated before this age.

The consequences of low thyroid hormone concentrations during critical illness remain controversial. Correla- tions between low thyroid hormone concentrations and adverse outcomes have been found, including increased mortality $[8,9,22]$. We did not find a significant difference in mortality rates between neonates with an aberrant screening result and neonates with a normal screening result. However, it should be noted that our sample size was small, and the results could have been biased by the lack of screening results for the 27 neonates who died before screening was performed.

As thyroid hormones are essential for early brain development, transiently reduced thyroid hormone concentrations during early life could affect neurodevelopment, which has been shown in premature infants [23, 24]. In that case, supplementation of thyroid hormones during NTIS could be beneficial. On the other hand, a recent study in young adults did not confirm this association between transient hypothyroxinemia of prematurity and adverse neurodevelopmental outcomes [25]. Furthermore, neonatal T4 supplementation was not beneficial in premature infants [26]. As levothyroxine therapy has not been proven to be beneficial, and thyroid hormone concentrations normalized rapidly in most cases, we do not advise starting levothyroxine therapy in EC$\mathrm{MO}$-treated neonates based on an aberrant screening result in the first 2 weeks of life.

To our knowledge, this is the first study reporting on $\mathrm{CH}$ screening results in ECMO-treated neonates with follow-up of thyroid function. A strength is the use of an efficient $\mathrm{CH}$ screening method. Further, this is the largest cohort study investigating $\mathrm{CH}$ screening results in EC$\mathrm{MO}$-treated neonates. Limitations are its retrospective design, its small sample size, and the lack of a strict schedule to follow up abnormal thyroid hormone concentrations. The small sample size does not allow drawing of a strong conclusion about the influence of the time of sampling during ECMO on screening results. Further, the exact date of normalization in some patients with abnormal thyroid hormone levels remains uncertain.

In conclusion, we found a higher incidence of aberrant $\mathrm{CH}$ screening results in neonates screened before (73.1\%) or during (67.3\%) ECMO than in neonates screened after (31.4\%) ECMO. All but 2 neonates (i.e. 98\%) with an aberrant screening result had low $\mathrm{T} 4$ concentrations with normal TSH, as is seen in NTIS. Thyroid hormone concentrations normalized rapidly in most, and none of these children was diagnosed with $\mathrm{CH}$. Our results suggest that T4 therapy is not required during ECMO. Follow-up of abnormal thyroid hormone concentrations is best performed after recovery from critical illness.
Leeuwen et al. 


\section{Acknowledgements}

We thank Ko Hagoort for editorial advice.

\section{Disclosure Statement}

The authors have no competing interests.

\section{References}

1 Oppenheimer JH, Schwartz HL: Molecular basis of thyroid hormone-dependent brain development. Endocr Rev 1997;18:462-475.

2 Kempers MJ, Lanting CI, van Heijst AF, van Trotsenburg AS, Wiedijk BM, de Vijlder JJ, Vulsma T: Neonatal screening for congenital hypothyroidism based on thyroxine, thyrotropin, and thyroxine-binding globulin measurement: potentials and pitfalls. J Clin Endocrinol Metab 2006;91:3370-3376.

3 Reuss ML, Leviton A, Paneth N, Susser M: Thyroxine values from newborn screening of 919 infants born before 29 weeks' gestation. Am J Public Health 1997;87:1693-1697.

4 Surks MI, Sievert R: Drugs and thyroid function. N Engl J Med 1995;333:1688-1694.

5 Marks SD, Haines C, Rebeyka IM, Couch RM: Hypothalamic-pituitary-thyroid axis changes in children after cardiac surgery. J Clin Endocrinol Metab 2009;94:2781-2786.

6 Fliers E, Bianco AC, Langouche L, Boelen A: Thyroid function in critically ill patients. Lancet Diabetes Endocrinol 2015;3:816-825.

7 Lim DJ, Herring MK, Leef KH, Getchell J, Bartoshesky LE, Paul DA: Hypothyroxinemia in mechanically ventilated term infants is associated with increased use of rescue therapies. Pediatrics 2005; 115:406-410.

8 Kurt A, Aygun AD, Sengul I, Sen Y, Citak Kurt AN, Ustundag B: Serum thyroid hormones levels are significantly decreased in septic neonates with poor outcome. J Endocrinol Invest 2011;34:e92-e96.

9 Goldsmit GS, Valdes M, Herzovich V, Rodriguez S, Chaler E, Golombek SG, Iorcansky S: Evaluation and clinical application of changes in thyroid hormone and TSH levels in critically ill full-term newborns. J Perinat Med 2011;39:59-64.

10 Stewart DL, Ssemakula N, MacMillan DR, Goldsmith LJ, Cook LN: Thyroid function in neonates with severe respiratory failure on extracorporeal membrane oxygenation. Perfusion 2001;16:469-475.
11 Stolar CJ, Snedecor SM, Bartlett RH: Extracorporeal membrane oxygenation and neonatal respiratory failure: experience from the extracorporeal life support organization. J Pediatr Surg 1991;26:563-571.

12 Pollack MM, Patel KM, Ruttimann UE: PRISM III: an updated pediatric risk of mortality score. Crit Care Med 1996;24:743-752.

13 Leteurtre S, Duhamel A, Salleron J, Grandbastien B, Lacroix J, Leclerc F; Groupe Francophone de Reanimation et d'Urgences Pédiatriques: PELOD-2: an update of the pediatric logistic organ dysfunction score. Crit Care Med 2013;41:1761-1773.

14 Lem AJ, de Rijke YB, van Toor H, de Ridder MA, Visser TJ, Hokken-Koelega AC: Serum thyroid hormone levels in healthy children from birth to adulthood and in short children born small for gestational age. J Clin Endocrinol Metab 2012;97:3170-3178.

15 Devilla L, Pende A, Morgano A, Giusti M, Musso NR, Lotti G: Morphine-induced TSH release in normal and hypothyroid subjects. Neuroendocrinology 1985;40:303-308.

16 Brabant G, Brabant A, Ranft U, Ocran K, Kohrle J, Hesch RD, von zur Muhlen A: Circadian and pulsatile thyrotropin secretion in euthyroid man under the influence of thyroid hormone and glucocorticoid administration. J Clin Endocrinol Metab 1987;65:83-88.

17 Van den Berghe G, de Zegher F, Lauwers P: Dopamine suppresses pituitary function in infants and children. Crit Care Med 1994;22: 1747-1753.

18 Samuels MH, Luther M, Henry P, Ridgway EC: Effects of hydrocortisone on pulsatile pituitary glycoprotein secretion. J Clin Endocrinol Metab 1994;78:211-215.

19 Filippi L, Pezzati M, Poggi C, Rossi S, Cecchi A, Santoro C: Dopamine versus dobutamine in very low birth weight infants: endocrine effects. Arch Dis Child Fetal Neonatal Ed 2007; 92:F367-F371.
20 Agus MS, Jaksic T: Critically low hormone and catecholamine concentrations in the primed extracorporeal life support circuit. ASAIO J 2004;50:65-67.

21 Leger J, Olivieri A, Donaldson M, Torresani T, Krude H, van Vliet G, Polak M, Butler G; ESPE-PES-SLEP-JSPE-APEG-APPES-ISPAE; Congenital Hypothyroidism Consensus Conference Group: European society for paediatric endocrinology consensus guidelines on screening, diagnosis, and management of congenital hypothyroidism. J Clin Endocrinol Metab 2014;99:363-384.

22 den Brinker M, Joosten KF, Visser TJ, Hop WC, de Rijke YB, Hazelzet JA, Boonstra VH, Hokken-Koelega AC: Euthyroid sick syndrome in meningococcal sepsis: the impact of peripheral thyroid hormone metabolism and binding proteins. J Clin Endocrinol Metab 2005;90:5613-5620.

23 Meijer WJ, Verloove-Vanhorick SP, Brand R, van den Brande JL: Transient hypothyroxinaemia associated with developmental delay in very preterm infants. Arch Dis Child 1992; 67:944-947.

24 Delahunty C, Falconer S, Hume R, Jackson L, Midgley P, Mirfield M, Ogston S, Perra O, Simpson J, Watson J, Willatts P, Williams F; Scottish Preterm Thyroid Group: Levels of neonatal thyroid hormone in preterm infants and neurodevelopmental outcome at $51 / 2$ years: millennium cohort study. J Clin Endocrinol Metab 2010;95:4898-4908.

25 Hollanders JJ, Israels J, van der Pal SM, Verkerk PH, Rotteveel J, Finken MJ, Dutch POPS-19 Collaborative Study Group: No association between transient hypothyroxinaemia of prematurity and neurodevelopmental outcome in young adulthood. J Clin Endocrinol Metab 2015;100:4648-4653.

26 Osborn DA, Hunt RW: Postnatal thyroid hormones for preterm infants with transient hypothyroxinaemia. Cochrane Database Syst Rev 2007:CD005945. 